\title{
The Solution for Optimal Power Flow (OPF) Method Using Differential Evolution Algorithm
}

\author{
Hazel Ariantara ${ }^{1}$, Sarjiya $^{2}$, Sasongko Pramono Hadi ${ }^{3}$
}

\begin{abstract}
Optimal Power Flow (OPF) is one of techniques used to optimize the cost of power plant production while maintaining the limit of system reliability. In this paper, the application of differential evolution (DE) method is used to solve the OPF problem with variable control such as the power plant output, bus voltage tension, transformer tap, and injection capacitor. The effectiveness of the method was tested using IEEE 30 buses. The result shows that this method is better than generic algorithm (GA), particle swarm optimized (PSO), fuzzy GA, fuzzy PSO, and bat-algorithm. The simulation of the power plant systems of $500 \mathrm{kV}$ Java-Bali with the proposed method can reduce the total cost of generation by $13.04 \%$ compared to the operating data PT. PLN (Persero).
\end{abstract}

Keywords- optimal power flow, differential evolution, variable control

\section{INTRODUCTION}

The need of electric power progressively increases along with the development of technology and the increase of population. It makes the demand for energy continue to rise. On the other hand, the energy supplied by the generator must be greater. Generally, to supply the energy, some power plants that are mutually interconnected are required in order to fulfil those needs. The utilization of electrical energy without an accurate calculation can effectively lead to the fuel surplus in each generating unit. Judging from the fuel consumption, most of it happens in the thermal power plant. The type of power plant in Indonesia is a thermal power plant type. In Java-Bali network, the contribution cost of fuel in the electricity production is about $60 \%$ from the total cost. Because of that, to reduce the price of electricity, the optimization costs on the process of electric production needed to be performed. In the interconnection power system, the optimization cost can be achieved by controlling the active and reactive power of each power plant. This method is called optimal power flow (OPF) [1].

In the OPF, controlled variable is used to minimize the power plant operational costs. The OPF also has restraints. It consists of calculating active power limit and reactive power plant; restrain the power capability from transmission system, transformer tap, and voltage plan [2].

1 Student, Dept. of Electrical Engineering and Information Technology, Faculty of Engineering, Universitas Gadjah Mada, Jl. Grafika No. 2 Kampus UGM Yogyakarta, 55281 INDONESIA (tlp: 0274-552305; e-mail: hazel.ariantara@gmail.com)

2, 3 Lecturer, Dept. of Electrical Engineering and Information Technology, Faculty of Engineering, Universitas Gadjah Mada, Jl. Grafika No. 2 Kampus UGM Yogyakarta, 55281 INDONESIA (tlp: 0274-552305
The OPF analysis has been developed from time to time. It evolves and becomes an algorithm which is applied successfully. There are several methods that have been developed. They are conventional optimization methods, such as newton method, quadratic programming (QP), linear programming (LP), and non-linear programming (NLP). It also occurs in the latest optimization methods, heuristic methods such as genetic algorithm (GA), particle swarm optimization (PSO), tabu search (TS), simulated annealing (SA), evolutionary programming (EP), etc. The conventional methods have several weaknesses, namely: heavily rely on the value of the initial guess, difficult to reach convergence, often getting stuck in optimum value, and relying heavily on the purpose and restriction of the system in order to optimize the global value [3]. In addition, the other research shows that the shortage of GA occurs because of the computing process which is slow. It occurs because there are many selection factors that must be processed [4]. Whereas, the PSO weakness is the possibility of the swarm state and reach the convergent state prematurely. This is due to the convergent of the global best particles PSO that is located on the line between the global best and personal best. At this point, it does not guarantee the best global solution.

On the previous research, the OPF has been accomplished using numerous conventional optimization techniques such as linear programming, non-linear programming, quadratic programming, newton method, dynamic programming, mixedinteger programming, decomposition technique, and interior point method [5] - [12]. The OPF problems were solved using PSO method. The objective is to minimize the power plant cost of IEEE 30 bus system. Then, the simulation results were compared with the gradient and GA method [13]. The problems also solved via the implementation of enhanced GA using roulette wheel to test IEEE 30 bus system and IEEE RTS-96 3-area [14]. In the previous study, OPF problems were solved using EP method to reduce the cost applied in IEEE 30 bus system. The simulation showed that EP method is better GA method. [15]. The hybrid tabu search and simulated annealing (TS/SA) have been used to minimize the OPF fuel cost by using multiple types of devices such as flexible alternating current transmission system (FACTS) [16]. The test on the IEEE 30 bus systems showed better results and required a shorter computation time instead of using GA, TS, or SA. On the other hand, fuzzy integration system with GA and PSO was used to solve the problems happened on OPF [17]. The test results on the IEEE 30 bus system showed it had better solution and was able to cut the computation time compared to standard methods of GA and PSO. 
Differential evolution (DE) is a new optimization method based on the evolutionary algorithm with the principles and philosophy algorithmically mimics the behaviour of biological evolution. DE can handle complex optimization problem, and simple coding so that it is easy to use [18]. In this journal, the $\mathrm{DE}$ has been proposed to solve the OPF problem with the objective to minimize total cost energy that used to generate electricity. Variable controls that have been used are the output of active power plants, bus voltage generator, transformer tap and capacitor injection. The effectiveness test of this method is performed in the case of IEEE 30 bus system and $500 \mathrm{kV}$ power system Java-Bali. Then, the simulation results were compared with the other heuristic methods.

\section{OPTIMAL POWER FLOW}

The OPF problem is a non-linear optimization problem with the objective function of non-linear and non-linear constraints. The OPF problem requires solution of non-linear equations; describing the optimal or safety operation of the energy system. OPF problems can be formulated as follows:

$$
\begin{array}{ll}
\text { Minimization } & F(x, u) \\
\text { with the provision } & G(x, u)=0 \\
& H(x, u) \leq 0 .
\end{array}
$$

where $F(x, u)$ as objective function that will be optimized. Generally, $G(x, u)$ is the balance of real power equation and reactive power, while $\mathrm{H}(\mathrm{x}, \mathrm{u})$ is safety limit. $x$ is dependent vector that consists of bus active power output with $\mathrm{P}_{\mathrm{G} 1}$ reference, magnitude voltage at load bus $\mathrm{V}_{\mathrm{L}}$, the output of reactive power plant $\mathrm{Q}_{\mathrm{G}}$, and the load of transmission line $\mathrm{S}_{\mathrm{L}}$.

$$
x^{\mathrm{T}}=\left[\mathrm{P}_{\mathrm{G} 1}, \mathrm{~V}_{\mathrm{L}}, \mathrm{Q}_{\mathrm{G}}, \mathrm{S}_{\mathrm{L}}\right]
$$

where $u$ as variable control that consists of the output of active power generator $\mathrm{P}_{\mathrm{G}}$, voltage magnitude at generator bus including bus reference $\mathrm{V}_{\mathrm{G}}$, transformer tap positions $\mathrm{T}$, and reactive power injection $\mathrm{Q}_{\mathrm{C}}$.

$$
u^{\mathrm{T}}=\left[\mathrm{P}_{\mathrm{G}}, \mathrm{V}_{\mathrm{G}}, \mathrm{T}, \mathrm{Q}_{\mathrm{C}}\right] .
$$

Mathematically the objective function of minimizing the fuel cost can be formulated as (6).

$$
F\left(P_{G i}\right)=\sum_{i}^{N_{C}} a_{i}+b_{i} P_{G i}+c_{i} P_{G i}^{2}
$$

Where $F$ is the total fuel cost generating, $a_{\mathfrak{i}}, b_{\mathfrak{i}}$, and $c_{\mathfrak{i}}$ is the coefficient generator fuel $i$, and $N_{G}$ is the number of generating units.

\section{A. The Linear Limit}

Linear limit $G(x, u)$ is the equation of real force balance and reactive force that can be expressed as follows.

$$
\begin{aligned}
& P_{G i}-P_{D i}-V_{i} \sum_{j=1}^{N_{B}} V_{j}\left(G_{i j} \cos \theta_{i j}+B_{i j} \sin \theta_{i j}\right)=0 \\
& Q_{G i}-Q_{D i}-V_{i} \sum_{j=1}^{\mathbb{N}_{B}} V_{j}\left(G_{i j} \sin \theta_{i j}+B_{i j} \cos \theta_{i j}\right)=0
\end{aligned}
$$

Where,

$$
P_{G i} \quad=\text { the output of active power at bus } i
$$

$$
\begin{array}{ll}
Q_{G i} & =\text { the output of reactive power at bus } i \\
P_{D i} & =\text { the needs of active power bus } i \\
Q_{D i} & =\text { the needs of reactive power at bus } i \\
N_{B} & =\text { total bus } \\
\theta_{i j} & =\text { the different phase between bus } i \text { dan bus } j \\
G_{i j} \text { dan } B_{i j}= & \text { admittance matrix elements between bus } i \\
& \text { dan bus } j
\end{array}
$$

\section{B. The Non-linear Limit}

Non-linear limit reflects the boundary of security system. The non-linear equation can be seen as follows.

1) Boundary Plant: Magnitude voltage plant, the output of active force and reactive power limited by lower and upper limit are as follows.

$$
\begin{aligned}
& V_{G i}^{\min } \leq V_{G i} \leq V_{G i}^{\max } ; \mathrm{i}=1, \ldots, N_{G} \\
& V_{G i}^{\min } \leq V_{G i} \leq V_{G i}^{\max } ; \mathrm{i}=1, \ldots, N_{G} \\
& Q_{G i}^{\min } \leq Q_{G i} \leq Q_{G i}^{\max } ; \mathrm{i}=1, \ldots, N_{G}
\end{aligned}
$$

2) Boundary Transformer: Transformer tap settings limited by the lower and upper limit are as follows.

$$
T_{\mathrm{i}}^{\min } \leq T_{\mathrm{i}} \leq T_{\mathrm{i}}^{\max } ; \mathrm{i}=1, \ldots, N_{T} .
$$

3) Boundary Compensator VAR: Reactive force injection on the bus limited by the lower and upper limit is as follows.

$$
Q_{C i}^{\min } \leq Q_{C i} \leq Q_{C i}^{\max } ; \mathrm{i}=1, \ldots, N_{C}
$$

4) Boundary Security: Boundary security system includes the magnitude of the voltage on each bus and transmission line charge. Systematically, boundary security can be formulated as follows.

$$
\begin{aligned}
& V_{\mathrm{Li}}^{\min } \leq V_{\mathrm{Li}} \leq V_{\mathrm{Li}}^{\max } ; \mathrm{i}=1, \ldots, N_{L} \\
& S_{\mathrm{Ii}} \leq S_{\mathbb{i l}}^{\max } ; \mathrm{i}=1, \ldots, N_{\mathbb{I}}
\end{aligned}
$$

\section{DIFFERENTIAL EVOLUTION}

DE is a method introduced by Kenneth Price and Rainer Storn in 1995 [19]. It is a multidimensional function of mathematical optimization method and the global optimization algorithm within evolution based. The idea of this algorithm is to presume the individual as a vector. Individual modification on mutation and re-combination is performed through the summation and subtraction of vector operations [20]. Along with the development, the DE becomes one of the best genetic algorithms. It can generate global optimum multidimensional (more than one optimum value) with a good probability.

Compared with the previous evolutionary algorithm method, the advantage of the DE is the presence of evolution which experienced by each individual in the population with differentiation and crossover. It occurs randomly and consecutively in each individual which is selected from the population every time. If the individual provides smaller value of function, new individual will replace it. Otherwise, the individual long maintained [21]. The optimization process is 
carried out through four basic operations, namely initialization, mutation, crossover, and selection.

\section{A. Initialization}

The algorithm begins from creating vector population which consists of individuals who evolve in each iterations/generations $g$. Each individual represents quantity vector that contains various elements of problem. The first step is to create an initial population from solution candidate by generating random values from each of them, which are upper and lower limit of each specified parameter. Generally, uniform distribution is used to generate the random number initialization because it is able to overcome the lack of information at the optimal point. The probability of uniform distribution from the random variable can be seen from the following equation.

$$
x_{j, i, 0}=\operatorname{rand}_{j}\left(b_{j, \text { maks }}-b_{j, \min }\right)+b_{j, \min }
$$

where

$$
\begin{aligned}
x_{j, i, 0}= & \text { the initial value parameter }-\mathrm{j} \text { with } \mathrm{g}=0 \text { from } \\
& \text { vector } i \\
\text { rand }_{j}= & \text { random numbers of uniform distribution from } \\
& \text { range }[0,1] \\
b_{j, \text { maks }}= & \text { upper limit } \\
b_{j, \text { min }}= & \text { lower limit }
\end{aligned}
$$

\section{B. Mutation}

After initialized, DE will mutate and re-combine the initial population to generate a new population. In the genetic context, mutation can be defined as the change of random elements. To control the mutation and improve convergence, deferential vector is scaled by a constant range $[0,2]$, which is called $\mathrm{F}$ constant (scaling factor). The (17) equation showing on how to form a mutant vector, $\mathrm{v}_{i, g}$.

$$
\mathrm{v}_{i, g}=\mathrm{x}_{\mathrm{r} 0, g}+F \cdot\left(\mathrm{x}_{\mathrm{r} 1, g}-\mathrm{x}_{\mathrm{r} 2, g}\right)
$$

where $\mathrm{r} 0, \mathrm{r} 1, \mathrm{r} 2$ are random indices, integers, and they must be different from others. Vector base index, Vector base index, r0, can be specified from various ways, such as random, permutation, stochastic, and random offset. Whereas, $\mathrm{r} 1$ and $\mathrm{r} 2$ are randomly selected from each mutation.

\section{Crossover}

To complete the search strategy, the DE uses crossover operation. The aim of crossover operation is to increase the diversity of the population parameter. Crossover generates vector test (trial vectors) from the value parameter that have been copied from two different vectors. The vector equation test can be seen as follow.

$$
u_{i, g}=u_{j i g}=\left\{\begin{array}{c}
v_{j i g} j i k a \text { rand }_{j} \leq c_{Y} \text { atau } j=j_{\text {rand }} \\
x_{j, i, g} \text { sebaliknya }
\end{array}\right.
$$

where

$$
\begin{aligned}
& \operatorname{rand}_{j}=\text { random uniform distribution with range }[0,1] \\
& \begin{aligned}
\mathrm{Cr} & =\text { constant crossover specified by consumer } \\
\mathbf{u}_{i, g} & =\text { test vector }
\end{aligned}
\end{aligned}
$$

$$
\begin{aligned}
\mathbf{v}_{i, g} & =\text { mutation vector } \\
\mathbf{x}_{i, g} & =\text { target vector. }
\end{aligned}
$$

The function of $\mathrm{Cr}$ is to control the refraction values of the parameters which are copied from the mutation. The test parameter that randomly selected index $j_{\text {rand }}$ is taken from mutations to ensure that the test vectors do not duplicate $\mathbf{x}_{i, g}$.

\section{Selection}

Selection operator chooses the vector that will compose the population in the next generation. If test vector $u_{i g}$ has the same value as objective function or lower than the target vector $x_{j i g}$, it will replace vector target on the next generation. On the contrary, the target population will maintain its position for at least one generation.

$$
x_{i_{i}+1}=\left\{\begin{array}{rr}
u_{i, g} & \text { jika } f\left(u_{i g}\right) \leq f\left(x_{i, g}\right) \\
x_{i g} & \text { sebaliknya }
\end{array}\right.
$$

The selection process for each pair of target or vector test will be repeated until the population from the next generation complete.

\section{E. Discontinuation Iteration Criteria}

After the new population is generated in the selection process, the process of mutation, recombination, and selection will be repeated until it reaches an optimal result. In some cases, reiteration until optimum globalization will take very long time. That's why the criteria that can stop the iteration time are needed. The limitations of iteration are as follow:

- the value of function at certain stage is reached,

- the performance of maximum number of iterations,

- statistical provision of a population is approaching at certain number, and

- provision length of time iteration

When the iteration limit is reached, the search for the optimum point will stop and the vector populations that have the best value will become the optimal point.

\section{RESULTS AND DiSCUSSION}

To determine the effectiveness of the OPF, the proposed method will be tested with the IEEE 30 bus system, before it was applied in Java-Bali system. This program was created and developed using Dell laptops Inspiron 1320 Intel ${ }^{\circledR}$ Core ${ }^{\mathrm{TM}} 2$ Duo@2.10GHz, 2.00 GB-RAM with Windows 7 and MATLAB software.

\section{A. IEEE 30 Bus System}

This system have six generating units with bus 1 as reference, 30 buses and 41 transmission lines with a total load of 283.4 MW. This system has 25 control variables, namely six unit active power plant output, six magnitude bus voltage, four tap transformer settings, and nine injection capacitors. The coefficient of power plant costs and limitations of IEEE 30 bus system are shown in Table I [22]. From the simulation which happened before optimization, DE obtained total cost $860.80 \$ /$ hour of power plant with the amount of transmission 
loss was 14.64 MW. Besides that, there is a violation on the limitation of the voltage and the transmission line.

In this case, the simulation is done using the following parameters:

$\begin{array}{ll}\mathrm{F} & =0.5 \\ \mathrm{CR} & =0.9 \\ \mathrm{NP} & =50 \\ \text { Iteration } & =200\end{array}$

The best results in the simulation which is conducted in ten experiments, are shown in Table II, with the amount of 800.50 \$/hour.

TABLE I

THE LIMITATION AND COEFFICIENT OF GENERATING COSTS

\begin{tabular}{|c|c|c|c|c|c|}
\hline \multirow{2}{*}{ No } & \multicolumn{3}{|c|}{ Coefficient Costs } & \multirow{2}{*}{ PG $_{\min }$} & \multirow{2}{*}{$\begin{array}{c}\text { PG }_{\max } \\
\text { (MW) }\end{array}$} \\
\cline { 2 - 4 } & $\mathbf{a}$ & $\mathbf{b}$ & $\mathbf{c}$ & 50 & 200 \\
\hline 1 & 0 & 2.00 & 0.00375 & 20 & 80 \\
\hline 2 & 0 & 1.75 & 0.01750 & 15 & 50 \\
\hline 3 & 0 & 1.00 & 0.06250 & 10 & 35 \\
\hline 4 & 0 & 3.25 & 0.00834 & 10 & 30 \\
\hline 5 & 0 & 3.00 & 0.02500 & 12 & 40 \\
\hline 6 & 0 & 3.00 & 0.02500 & & \\
\hline
\end{tabular}

TABLE II

OPF-DE SIMULATION RESULTS WITH IEEE 30 BUS SYSTEM

\begin{tabular}{|c|c|}
\hline Power Plant & Load (MW) \\
\hline $\mathrm{P}_{1}$ & 177,004 \\
\hline $\mathrm{P}_{2}$ & 48,715 \\
\hline $\mathrm{P}_{3}$ & 21,390 \\
\hline $\mathrm{P}_{4}$ & 21,300 \\
\hline $\mathrm{P}_{5}$ & 12,006 \\
\hline $\mathrm{P}_{6}$ & 12,000 \\
\hline Total Cost(\$/hour) & 800,50 \\
\hline Total loses (MW) & 9,028 \\
\hline
\end{tabular}

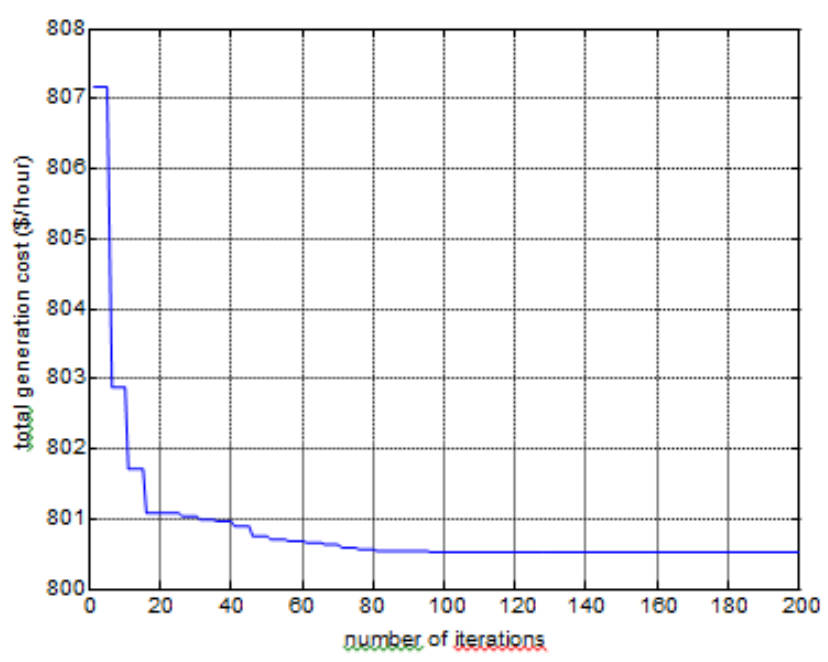

Fig. 1 The total cost of power plant in IEEE 30 bus system.

Fig. 1 shows total power plant cost which the optimal value could be reached before iterating $100^{\text {th }}$. From these results, there was $60.30 \$ /$ hour (7\%) saving and total of transmission losses is $5.61 \mathrm{MW}(38.3 \%)$. Moreover, the voltage magnitude of each bus was still in specified operation limits, with lower limit provision was $(0.95 \mathrm{pu})$ and upper limit provision was $(1.05 \mathrm{pu})$, as shown in Fig. 2. Meanwhile, the power flow in each channel was still within the operation boundaries with the transmission line at the highest channel $91 \%$ on bus 1 to bus 2 . This is because the power plant at bus 1 (reference bus) receive greater load than the other plant. The results of imposition channel simulation are shown in Fig. 3.

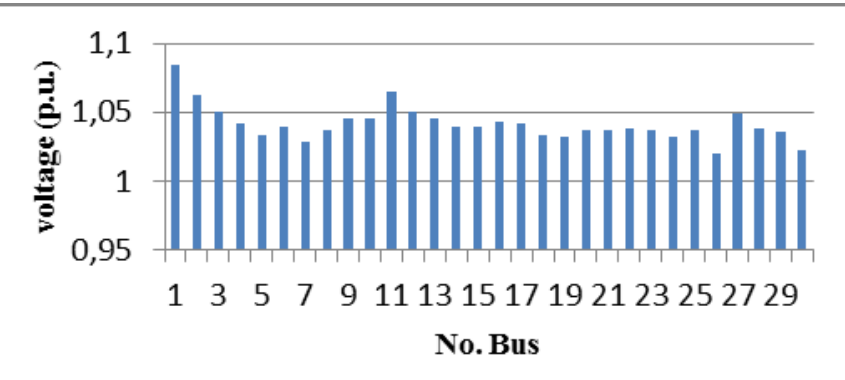

Fig. 2 Voltage profile bus after optimization OPF-DE.

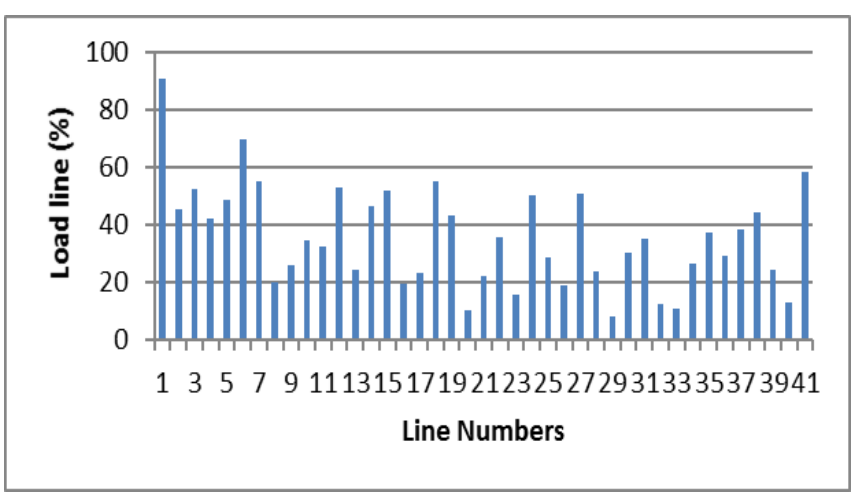

Fig. 3 Imposition channel after optimization OPF-DE.

TABLE III

THE COMPARISON OF SIMULATED RESUltS IN IEEE 30 BUS SySTEMS

\begin{tabular}{|l|c|c|}
\hline $\begin{array}{c}\text { Optimization } \\
\text { Method }\end{array}$ & $\begin{array}{c}\text { Power Plant Cost } \\
\mathbf{( \$ / h o u r )}\end{array}$ & Transmission Loss \\
\hline DE & $\mathbf{8 0 0 . 5 0 0}$ & $\mathbf{9 . 0 2 8}$ \\
\hline GA [17] & 801.960 & 9.080 \\
\hline FGA [17] & 801.121 & 9.030 \\
\hline PSO [17] & 800.960 & 9.080 \\
\hline FPSO [17] & 800.720 & 8.750 \\
\hline Bat Algorithm[23] & 800.929 & 9.220 \\
\hline
\end{tabular}

The comparison of simulation results in the DE with the proposed methods such as GA method [17], fuzzy GA [17], PSO [17], fuzzy PSO [17], and bat algorithm [23] can be seen in Table III. The results show that the cost saving is $\$ 0.22$ /hour compared to the FPSO and \$0.429/hour compared to the bat algorithm method. Based on Table III, it can be concluded that the DE method is more reliable and could be applied in real system.

\section{B. 500 kV Java-Bali System}

The Java-Bali $500 \mathrm{kV}$ system used in this study refers to two previous studies [23], [24]. This system consists of eight stations, 25 buses and 30 transmission lines. Surayala power plant unit is the reference bus while the Muaratawar, Cirata, 
Saguling, Tanjung Jati, New Gresik, Grati, and Paiton acted as generator bus (PV). One line diagram system of Java-Bali 500 $\mathrm{kV}$ is presented in Fig. 4. Among those 8 power units, 2 units are PLTAs, and 6 units are thermal power plants. Table IV shows the power plant function.

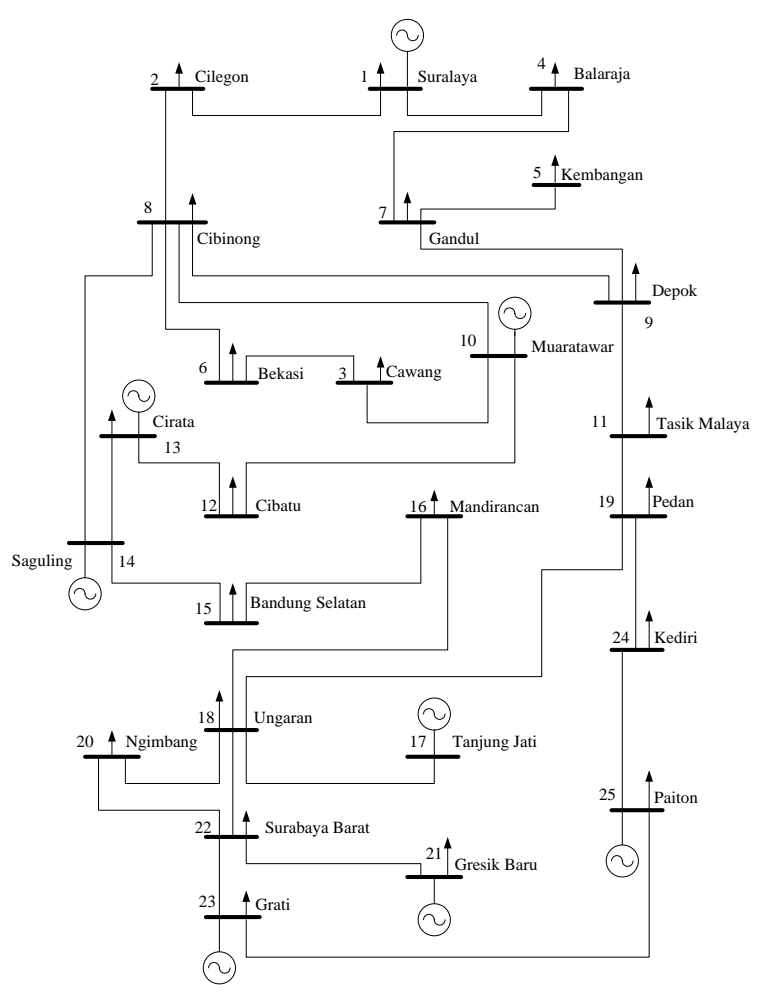

Fig. 4 Java-Bali $500 \mathrm{kV}$ one line diagram.

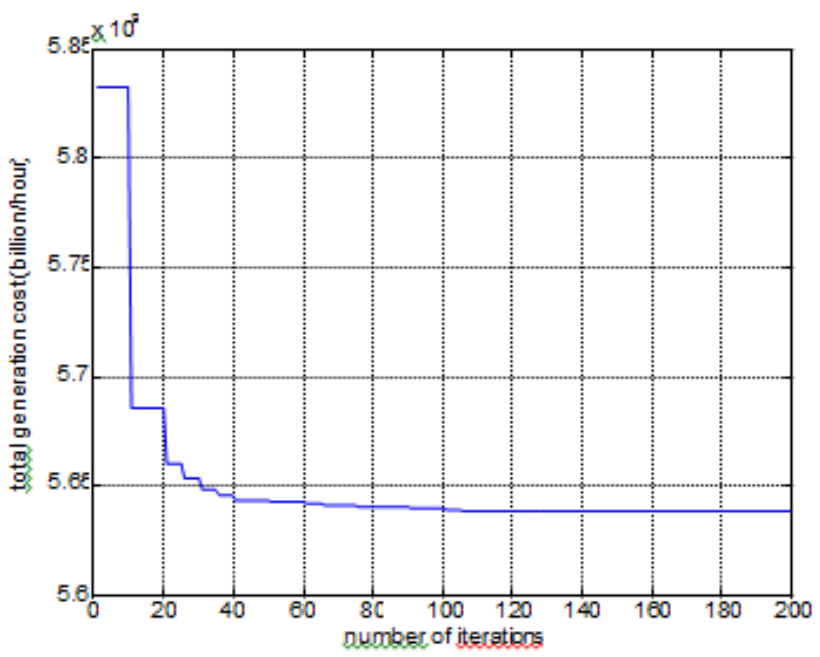

Fig. 5 Total cost of generating power plant in Java-Bali system.

The simulation was performed in the single peak load on 30 November 2011 at 19:00 with 12.058 MW total loads. The simulations can be seen in Fig. 5. Cirata and Saguling PLTA power plants were deemed as appropriate PLN operating data because the calculation power plant cost for PLTA was different. The PLTA operation itself should pay attention to water reserves, reservoir operation, and others. Based on the power plant data, total power plan cost was PLN's (Persero)
Rp. 6,483,652,226.25/hour with total losing amounting up to 130.94 MW transmission. The simulation of Java-Bali OPFDE system was tested ten times. The best result for this simulations with total power plant cost was Rp. $5,638,121,187.23$ /hour with transmission loss up to 282,388 MW. Fig. 5 shows that the cost of power plant had entered converging area which is at the 40th iteration from total 200 iterations. Table $\mathrm{V}$ shows the comparison results of power plant simulation from each power plant in MW. The power plant is obtained from PT. PLN.

TABLE IV

THE COST FUNCTION OF 500 KV JAVA-BALI

\begin{tabular}{|l|c|}
\hline Power Plant & Power Plant Function \\
\hline Suralaya & $-7.9 \mathrm{P}^{2}+407989.96 \mathrm{P}+47071299.80$ \\
\hline Muaratawar & $-116.23 \mathrm{P}^{2}+1322770.66 \mathrm{P}-$ \\
& 196885587.43 \\
\hline Tanjung Jati & $34.75 \mathrm{P}^{2}+199772.39 \mathrm{P}+104589684.82$ \\
\hline Gresik & $2.68 \mathrm{P}^{2}+831821 \mathrm{P}+81256913.02$ \\
\hline Grati & $76.96 \mathrm{P}^{2}+1173763.42 \mathrm{P}+$ \\
& 199704022.52 \\
\hline Paiton & $-35.21 \mathrm{P}^{2}+466601.72 \mathrm{P}+5600093.12$ \\
\hline
\end{tabular}

TABLE V

THE COMPARISON BETWEEN DATA SIMULATION RESUlTS WITH OPERATION DATA FROM PLN

\begin{tabular}{|l|c|c|}
\hline \multicolumn{1}{|c|}{ Power Plant } & PLN & DE \\
\hline Suralaya & 2735 & 1900.31 \\
\hline Muaratawar & 1785 & 1400.40 \\
\hline Tanjung Jati & 1971 & 1869.04 \\
\hline Gresik & 1371 & 895.63 \\
\hline Grati & 441 & 305.80 \\
\hline Paiton & 2572 & 4713.20 \\
\hline Total cost (Rp) & $\mathbf{6 , 4 8 3 , 6 5 2 , 2 2 6}$ & $\mathbf{5 , 6 3 8 , 1 2 1 , 1 8 7}$ \\
\hline Total losses (MW) & $\mathbf{1 3 0 . 9 4 0}$ & $\mathbf{2 8 2 . 3 8 8}$ \\
\hline
\end{tabular}

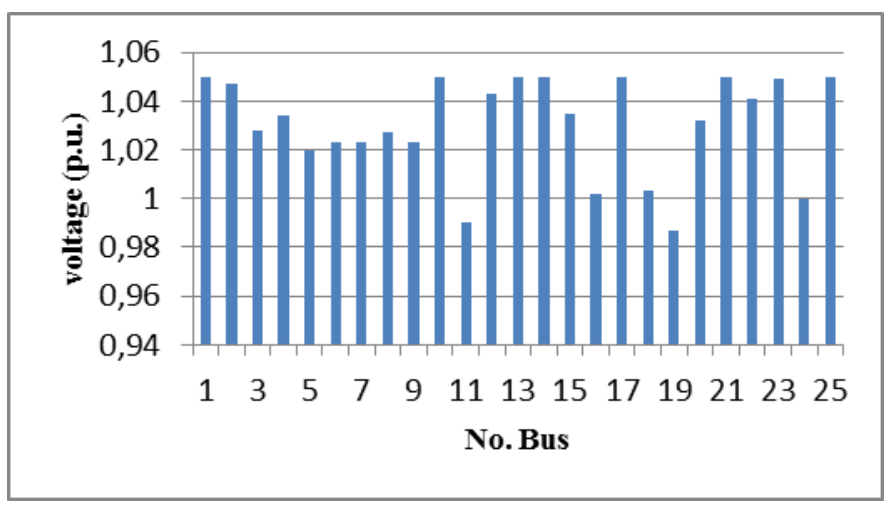

Fig. 6 The voltage profile of Java-Bali bus system.

The proposed method can reduce the power plant cost by Rp. $845,531,039 /$ hour or $13.04 \%$ with total losses 282.39 MW. The escalation in transmission loss was caused by the transition of several service loads from close loads which was far away from power plant. Although the cost is minimal, it was far away from load centres. However, the increase of these losses did not affect the quality of voltage bus because each load was still in minimum limit. The minimum limit set by PLN is in accordance with the Grid Code (network rules 2007 ), was $\pm 5 \%$ of nominal voltage for $500 \mathrm{kV}$ system. 


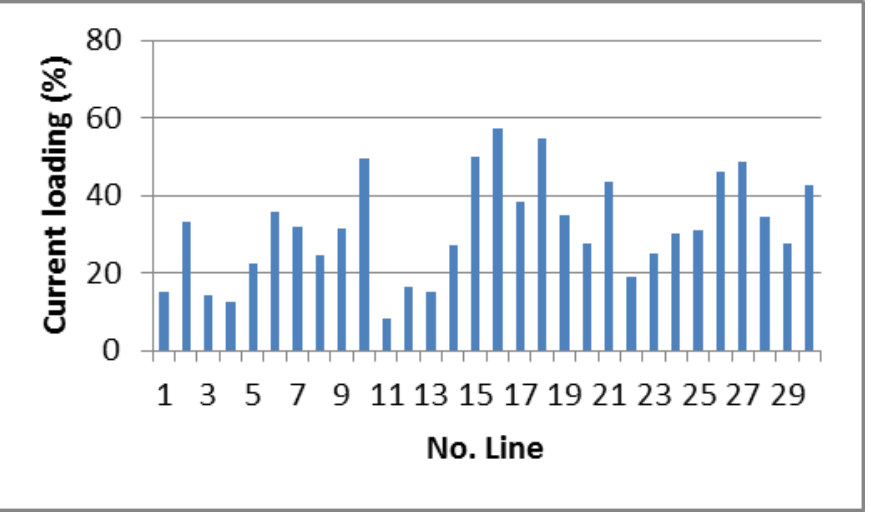

Fig. 7 Transmission line loading of $500 \mathrm{kV}$ Java-Bali system.

The voltage reading from each bus is still in the safe limits, as shown in Fig. 6. Meanwhile, the load system of the JavaBali in each line located within the operation limit is in loading operation of $500 \mathrm{kV}$, as shown in Fig. 7.

\section{CONCLUSION}

In this paper, the differential evolution method is proposed to solve the OPF problems. The simulation of the IEEE 30 bus system and $500 \mathrm{kV}$ Java-Bali power can be summed up as follows. In the IEEE 30 bus system, the DE method can reduce the power plant cost $0.18 \%$ compared to the GA method and decrease $0.05 \%$ compared with the PSO and BA method. In $500 \mathrm{kV}$ Java-Bali power system, the DE method can reduce the total cost of power plant by Rp. $845,531,039 /$ hour or by $13.04 \%$ compared with PT. PLN (Persero's) operating data. Moreover, from the simulation results, it can be concluded that the cost of power plant has reached converging at the 40th iteration. It indicates that the method is able to reach the optimal value quickly.

\section{REFERENCE}

[1] Hadi Saadat, Power System Analysis, New York: WCB McGraw-Hil, 1999.

[2] A.J. Wood and B.F. Wollenberg, Power Generation, Operation and Control", New York: Wiley-Interscience, 1996.

[3] S. Frank, I. Steponavice, and S. Rebennack, "Optimal power flow: a bibliographic survey I", Energy Syst., vol. 3, no. 3, pp. 221-258, Apr.2012.

[4] Frans van den Bergh and Andries P. Engelbrecht, "A cooperative approach to particle swarm optimization", IEEE Transactions on Evolutionary Computation, vol. 8 ,no.3, pp. 225 - 239, 2004

[5] Kirschen DS dan Van Meeteren HP, "MW/Voltage control in linear programming based optimal power flow", IEEE Trans Power Syst. 3 (4): $481-9,1988$.

[6] G.L.Torres and V.H. Quintana, "An interior-point method for nonlinear optimal power flow using rectangular coordinates", Trans. Power Syst. 13 (4), 1211- 1218, 1998.
[7] Quintana, V.H., Santos - Nieto, M, "Reactive-power dispatch by successive quadratic programming", IEEE Trans. Energy Convers.,4,(3), pp. 425 - 435, 1989.

[8] D.I. Sun, B. Ashley, B. Brewar, A. Hughes, and W.F. Tinny, "Optimal power flow by Newton approach", IEEE Trans. Power Appar and Syst., 103,(2), pp.2864 - 2878, 1984.

[9] F.C. Lu and Y.Y. Hsu, "Reactive power / Voltage control in a distribution substation using dynamic programming", IEEE Proceeding - Generation, Transmission and Distribution, 142(6), pp 639 - 645, 1995.

[10] K. Aoki, M. Fan, and A. Nishikori, "Optimal VAR planning by approximation method for recursive mixed-integer linear programming", IEEE Transactions on power Systems, 3(4), pp 1741 1747,1998

[11] N. Deeb and S. M. Shahidehpour, "Linear reactive power optimization in a large power network using the decomposition approach", IEEE Transactions on power systems, 5(2), pp.428-438, 1990.

[12] S. Granville, "Optimal reactive dispatch through interior point methods", IEEE Transactions on power systems, 9 (1), pp. 136 - 146 1994.

[13] M. A. Abido, "Optimal power flow using particle swarm optimization,” Electr. Power Energy Syst., vol. 24, pp. 563-571, 2002.

[14] Bakirtzis G., Biskas P. N., Zoumas C. E., and Petridis V., "Optimal Power Flow by Enhanced Genetic Algorithm," IEEE Transaction on Power System, Vol. 17, No. 2, pp. 229-236, May 2002.

[15] Y. Sood, "Evolutionary programming based optimal power flow and its validation for deregulated power system analysis," Int. J. Electr. Power Energy Syst., vol. 29, no. 1, pp. 65-75, Jan. 2007.

[16] W. Ongsakul, P. Bhasaputra.Optimal, "Power flow with FACTS devices by hybrid TS/SA approach", International Journal of Electrical Power \& Energy Systems, 24(10), pp.851-857, 2002.

[17] S. Kumar and D. K. Chaturvedi, "Optimal power flow solution using fuzzy evolutionary and swarm optimization," Int. J. Electr. Power Energy Syst., vol. 47, pp. 416-423, May 2013.

[18] Storn, R and Price, K "Differential Evolution - A Simple and Efficientm Adaptive Scheme for Global Optimization over Continuous Spaces". Technical Report, International Computer Science Institute, Berkley, 1995.

[19] Price, K.V., Storn, R.M., and Lampinen, J.A., Differential Evolution: A Practical Approach to Global Optimization. Natural Computing Series. Berlin: Springer-Verlag, 2005.

[20] R. Storn and K. Price, Journal of Global Optimization, 11, pp.341-359, 1997.

[21] Aplikasi Algoritma Differential Evolution untuk Permasalahan Kompleks Pemilihan Portofolio. Accessed at http://digilib.its.ac.id/public/ITS-Undergraduate-12647-Paper.pdf. On 10 June 2014.

[22] K. Y. Lee, Y. M. Park, and J. L. Ortiz, "A United Approach to Optimal Real and Reactive Power Dispatch", IEEE Trans. Power Appar. Syst. vol. PAS-104, no. 5, pp. 1147-1153,1985.

[23] Z. Abidin, "Studi optimal power flow menggunakan metode bat algorithm", Thesis, Universitas Gadjah Mada, 2014.

[24] Yassir, "Studi optimal power flow sistem kelistrikan $500 \mathrm{kV}$ Jawa Bali dengan menggunakan metode algoritma genetika", Thesis, Universitas Gadjah Mada, 2013. 